chúng tôi là $0 \%$, có thể là do nhiêu nguyên nhân, trong đó hầu hết các trường hợp nặng, nguy cơ cao đã được đình chỉ thai nghén trước khi sinh. Hiểu biết rõ hơn về bệnh lý này cũng như các phương pháp phẫu thuât cũng khiến cho kết quả điều trị cải thiện hơn, giảm thiểu tỉ lệ tử vong và biến chứng.

Theo dõi xa ở thời điểm 9 tháng, tỉ lệ rối loan cơ tròn ở nhóm bệnh thoát vị màng tuý là $72 \%$, thấp hơn so với của Phạm Hồng Huân (98\%) [1] và Greenberg (90\%) [5]. Tương tự vậy, tổn thương vận động và cảm giác khi theo dõi xa trong nghiên cứu của chúng tôi là $31,6 \%$, thấp hơn so với Greenberg (40\%) [5].

Chụp cộng hưởng từ đánh giá tình trạng tuỷ bám thấp cho thấy có sự cải thiện ( $7 \%$ so với 3,5\% trước mổ).

Đánh giá về chất lượng cuộc sống theo thang điểm Kanofsky, có đến $80 \%$ số bệnh nhân trong nghiên cứu của chúng tôi có thể sống độc lập, có thể tự chăm sóc bản thân. Triệu chứng gây phiền hà nhất đó là đái rỉ, thường gây khó khăn hơn ở nhóm bệnh nhi so với người trưởng thành.

\section{KẾT LUÂ̂N}

Bệnh lý thoát vị tuỷ-màng tuỷ là một tổn thương bẩm sinh dù đã có rất nhiều tiến bộ trong chẩn đoán, điều trị thoát vị tuỷ màng tuỷ ở trẻ em, song vẫn là một thách thức đối với chuyên ngành phẫu thuật thần kinh. Nghiên cứu này góp phần làm rõ thêm tình trạng hiện tại của bệnh lý này trong thực hành lâm sàng.

\section{TÀI LIÊU THAM KHẢO}

1. Huân, P.H., Nghiên cứu điều trị thoát vị tủy màng tủy vùng thắt lưng - cùng ở trẻ em. 2006, Đại học Y Dược Thành phố HCM.

2. Lorber, J., Results of treatment of myelomeningocele. An analysis of 524 unselected cases, with special reference to possible selection for treatment. Dev Med Child Neurol, 1971. 13(3): p. 279-303.

3. Vinh, T.Q., Ứng dụng của phương pháp kích thích thần kinh cơ trong phẫu thuật thoát vị tủy màng tủy. Y học thành phố Hồ chí Minh, 2012. 16(4): p. 247-252.

4. Özek, et al., Spina Bifida. 2008.

5. Greenberg, M.S. and N. Arredondo, Handbook of Neurosurgery 6th ed. 2006 Lakeland, FLNew York: Greenberg Graphics; Thieme Medical Publishers.

6. Pier, D.B., et al., Magnetic resonance volumetric assessments of brains in fetuses with ventriculomegaly correlated to outcomes. J Ultrasound Med, 2011. 30(5): p. 595-603.

7. Chern, J.J., et al., Clinical evaluation and surveillance imaging in children with spina bifida aperta and shunt-treated hydrocephalus. J Neurosurg Pediatr, 2012. 9(6): p. 621-6.

\title{
THỰC TRANG MẮC BÊNHH BỤI PHỔI SILIC CỦA NGƯỜI LAO ĐộNG TRONG MộT SỐ CÔNG TY TẠI PHÚ YÊN NĂM 2020
}

\author{
Lê Thị Thanh Xuân', Lê Thị Hương1, Khương Văn Duy¹, \\ Nguyễn Ngọc Anh', Nguyễn Thanh Thảo', Phạm Thị Quân ${ }^{1}$, \\ Nguyễn Quốc Doanh ${ }^{1}$, Phan Thị Mai Hương ${ }^{1}$, Tạ Thị Kim Nhung', \\ Lương Mai Anh², Nguyễn Thị Thu Huyền²
}

\section{TÓM TẮT}

Mục tiêu: Mô tả tỷ lệ hiện mắc bệnh bụi phổi silic của người lao động (NLĐ) tiếp xúc trực tiếp với bụi silic ở một số cơ sở sản xuất tỉnh Phú Yên năm 2020. Phương pháp: nghiên cứu mô tả cắt ngang. Kết quả: Tỷ lệ hiện mắc bệnh bụi phổi silic của NLĐ tiếp xúc trực tiếp với bụi silic trong một số ngành nghề tại Phú Yền năm 2020 là 1,8\%. NLẺ mắc bệnh bụi phổi silic tập trung ở loại hình sản xuất đá granit (100\%).

${ }^{1}$ Viện ĐT YHDP\&YTCC, Trường Đại học Y Hà Nội ${ }^{2}$ Cưc Quản lý môi trướng Y tế - Bồ Y tế

Chịu trách nhiệm chính: Lê Thị Thanh Xuân

Email: lethithanhxuan@hmu.edu.vn

Ngày nhận bài: 22.10 .2020

Ngày phản biên khoa học: 24.11.2020

Ngày duyệt băi: 7.12.2020
Tỷ lệ NLĐ có các triệu chứng ho, khạc đờm, đau ngực, khó thở, rì rào phế nang giảm lấn lượt là $6,8 \%, 7,7 \%$, $2,3 \%, 2,3 \%, 0,5 \%$. Các tổn thương đám mờ nhỏ trên phim X-quang theo tiêu chuẩn ILO của NLĐ đều thuốc phân nhóm chính nhóm 1 . Trong đó, tổn thương đám mờ nhỏ có mật độ $1 / 1$ chiếm đa số với 75,0\%. 100\% các đám mờ nhỏ trên phim X-quang đều có kích thước loai $\mathrm{p} / \mathrm{p}$. Đa số NLĐ không có rối loạn thông khí. Tỷ lệ NLĐ có rối loạn thông khí han chế là $10,9 \%$. Tỷ lể NLĐ có rối loạn thông khí tắc nghẽn là $6,4 \%$. Kết luận: đa số NLĐ không mắc bệnh bụi phổi silic, các rối loan thông khí và tổn thương nhu mô phổi trên phim X - quang mà NLĐ găp phải đa số là thể nhẹ.

Tư khóa: bệnh bụi phổi silic, Phú Yên, 2020.

\section{SUMMARY}

THE SITUATION OF SILICOSIS OF WORKERS IN SOME COMPANIES IN 


\section{PHU YEN IN 2020}

Objective: The study aimed to describe the prevalence of silicosis among workers who were directly exposed to silica in some factories in Phu Yen province in 2020. Method: cross-sectional studies. Results: The prevalence of silicosis of workers in direct expose with silicon dust in some factories in Phu Yen in 2020 was $1.8 \%$. Employees suffering from silicosis concentrate on granite production (100\%). The percentage of employees with symptoms of cough, sputum, chest pain, breathless, whispered alveolar decreased by $6.8 \%, 7.7 \%, 2.3 \%, 2.3 \%$, $0.5 \%$, respectively. Small opacities on X-ray films according to ILO standards belonged to the main group 1. In which, small opacities with density $1 / 1$ accounted for the majority with $75.0 \% .100 \%$ of the small opacities on X-ray films were $p / p$ size. Most employees did not have respiratory dysfunction. The rate of employees with the limited disorder was $10.9 \%$. The rate of employees with the obstructive disorder was $6.4 \%$. Conclusion: Most employees did not suffer from silicosis, respiratory dysfunction and lung damage on X-ray film, most of them were mild.

Keywords: silicosis, Phu Yen, 2020.

\section{I. ĐĂT VẤN ĐỀ}

Bênh bui phổi silic là tình trang bênh lý ở phổi do thở hít bioxit silic $\left(\mathrm{SiO}_{2}\right)$ hoặc silic tự do. Đặc điểm của bệnh về mặt giải phẫu là xơ hóa và phát triển các hạt ở hai phổi, về mă̆t lâm sàng là khó thở và về mặt X-quang là phổi có hình ảnh tổn thương đặc biệt. Việc tiếp xúc với bụi trong môi trường lao động (MTLĐ), đặc biệt là những ngành nghề phát sinh nhiều bụi $\mathrm{SiO}_{2}$ cũng làm tăng nguy cơ mắc các bệnh hô hấp nghề nghiệp ở NLĐ, đặc biệt là bệnh bụi phổi Silic. Theo thống kê của Tổ chức lao động Quốc tế (ILO), ước tính mỗi năm có khoảng 2,02 triệu người chết có nguyên nhân từ bệnh nghề nghiệp, con số này tương đương với khoảng 5.500 người chết mối ngày[1],[2]. Theo báo cáo của Cục Quản lý Môi trường y tế, số ca mắc bệnh bụi phổi silic nghề nghiệp có xu hướng tăng lên. Phú Yên là tỉnh có tiềm năng về khoáng sản làm vật liệu xây dựng và chế tác thủ công mỹ nghệ, trong đó đáng chú ý nhất là ngành khai thác, chế biến đá granit. Đây là những ngành công nghiệp gây ra ô nhiễm bụi trong MTLĐ, đặc biệt là bụi dioxyd silic tự do $\left(\mathrm{SiO}_{2}\right)$. Trên thế giới cũng như ở Viêt Nam, việc nghiên cứu về ảnh hưởng của bụi silic lên các bênh hô hấp của người lao động (NLĐ) là khá phổ biến, tuy nhiên với tình trạng mắc bệnh ngày càng gia tăng phức tạp như hiên nay thì việc tiến hành thêm một nghiển cứu để làm rõ ảnh hưởng của MTLĐ phát sinh nhiều bụi silic đến việc gia tăng tình trạng mắc bệnh bụi phổi silic là cần thiết. Vì vậy, nghiên cứu được tiến hành với mục tiêu sau: mô tả tỷ lệ hiện mắc bệnh bụi phổi silic của người lao động tiếp xúc trực tiếp với bụi silic ở một số cơ sở sản xuất tỉnh Phú Yên năm 2020. Kết quả nghiên cứu sẽ định hướng cho các cơ quan chức năng và doanh nghiệp đề ra những chính sách phù hợp nhăm bảo vệ sức khỏe, phòng chống bệnh bụi phổi silic nghề nghiệp cho NLE.

\section{II. ĐỐI TƯợNG VÀ PHƯƠ'NG PHÁP NGHIÊN CỨU}

2.1. Đối tượng nghiên cứu. NLĐ tiếp xúc trực tiếp với bụi silic trong MTLĐ.

- Tiêu chuẩn lựa chọn đối tượng: NLĐ tiếp xúc trực tiếp với bụi silic trong MTLĐ đồng ý tham gia nghiên cứu và tham gia khám đầy đủ các mục phát hiện bệnh nghề nghiệp.

- Tiêu chuẩn loại trừ đối tượng: Những đối tượng tham gia khám sức khỏe nhưng không khám đầy đủ các mục như bệnh án nghiên cứu (đo chiều cao, cân nặng, chức năng hô hấp, chụp phim Xquang và khám hô hấp), phụ nữ có thai, vắng măt taii thời điểm điều tra.

\subsection{Phương pháp nghiên cứu}

2.2.1. Thiết kế nghiên cứu: Nghiên cứu mô tả cắt ngang

\subsubsection{Cỡ mẫu, chọn mẫu:}

- Cõ̃ mẫu toàn bộ

- Chọn mẫu: Chọn mẫu chủ đích: chọn chủ đích các công ty có phát sinh bụi silic trong MTLĐ theo danh sách các công ty/doanh nghiêp trong tỉnh Phú Yên có hồ sơ quản lý vệ sinh lao động của Trung tâm kiểm soát bệnh tật tỉnh Phú Yền. Sau đó chọn toàn bộ NLĐ có tiếp xúc trực tiếp với bụi silic ở các công ty lựa chọn theo tiểu chuẩn nghiên cứu.

2.3. Thời gian nghiên cứu: Thời gian thực hiện nghiên cứu từ tháng $9 / 2019$ đến tháng 12/2020.

2.4. Công cư và phương pháp thu thập số liệu. Thông tin được thu thập theo bệnh án nghiên cứu dựa theo hồ sớ khám sức khỏe phát hiện bênh nghề nghiệp theo mẫu chuẩn của Bộ Y tế và có bổ sung các biến số, chỉ số nghiên cứu.

Trong nghiên cứu này, chúng tôi áp dụng người lao động mắc bệnh bưi phổi silic khi 1) có tiếp xúc trực tiếp với bụi silic và 2) có tổn thương trên phim $X$ quang theo ILO như đã trình bày ở trên.

2.5. Xử lý số liệu. Số liệu được làm sạch, mã hóa và nhập vào phần mềm EpiData 3.1. Số liệu được phân tích trên phần mềm Stata 14.0. Thống kê mô tả áp dụng để trình bày các tần suất, tỷ lệ \%. Test Khi bình phương và Fisher exact test được áp dụng để so sánh hai tỷ lệ giữa các nhóm. Mức ý nghĩa thống kê 0,05 được áp dụng. 
2.6. Đạo đức nghiên cứu. Nghiên cứu này là một phần trong đề tài nghiên cứu khoa học cấp nhà nước "Nghiên cứu đặc điểm dịch tễ học phân tử, yếu tố nguy cơ và ứng dụng kỹ thuật tiên tiến trong chẩn đoán sớm bệnh bụi phổi silic tại Việt Nam", mã số: KC10/1620. Vấn đề nghiên cứu không ảnh hưởng tới sức khỏe cũng như các vấn đề về khác của đối tượng. Các thông tin thu thập được từ các đối tượng chỉ phục vụ cho mục đích nghiên cứu và hoàn toàn được giữ bí mật.

III. KẾT QUẢ NGHIÊN CỨU

Bảng 1. Tỷ lệ hiện mắc bệnh bụi phổi silic của người lao động ( $n=220)$

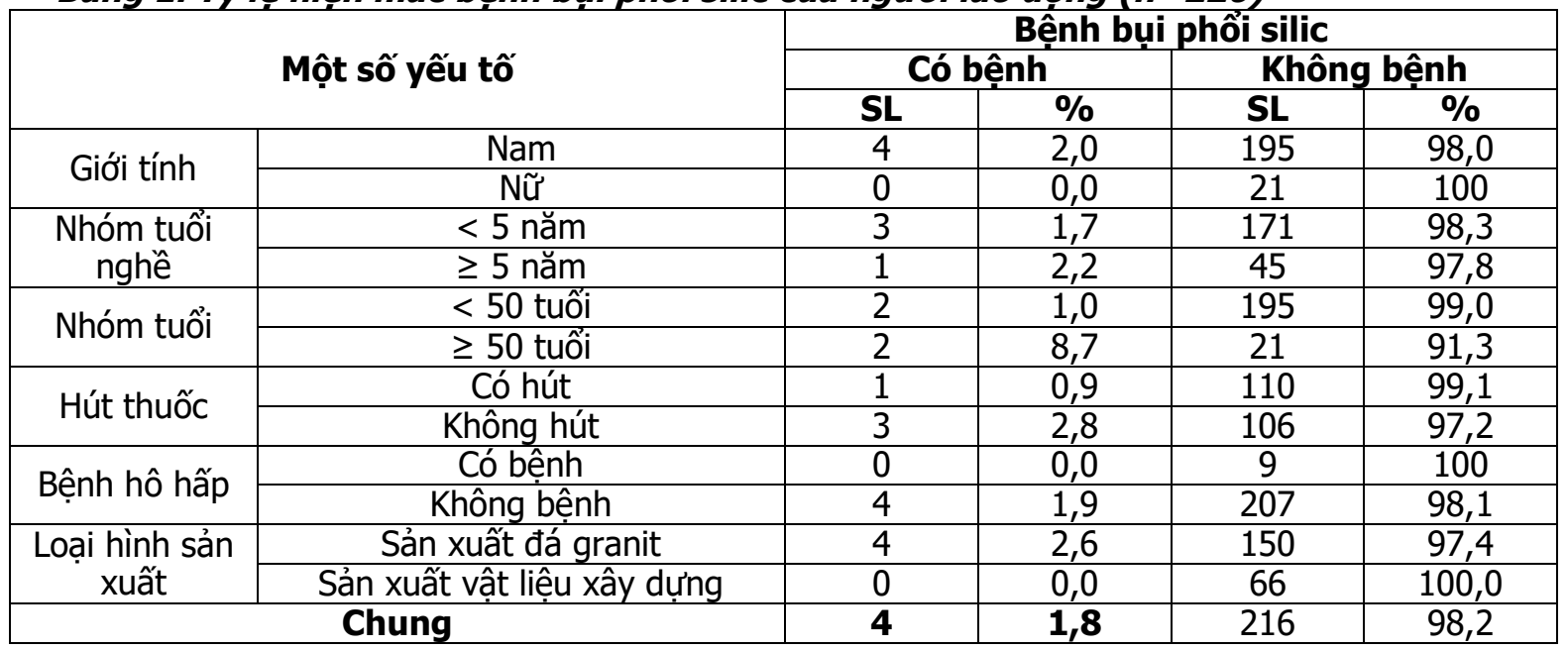

Tỷ lệ hiện mắc bênh bụi phổi silic của NLĐ ở các nhà máy qua khám lâm sàng và chụp phim $X$ quang theo ILO năm 2020 là 1,8\%.

Trong đó, tỷ lệ hiện mắc bệnh bụi phổi silic ở lao động nam là $2,0 \%$. Chưa có lao động nữ nào mắc bệnh bụi phổi silic.

Tỷ lệ lao động có tuổi nghề từ 5 năm trở lên mắc bệnh bụi phổi silic là $2,2 \%$ cao hơn tỷ lệ lao động dưới 5 năm mắc bệnh bụi phổi silic $(1,7 \%)$.

Tỷ lệ hiên mắc bệnh bui phổi silic của nhóm lao động từ 50 tuổi trở lên là $8,7 \%$, cao hơn tỷ lệ hiện mắc bệnh bụi phổi silic của nhóm lao động dưới 50 tuổi $(1,0 \%)$.

Những NLĐ được chẩn đoán mắc bệnh bụi phổi silic đều tập trung ở loại hình sản xuất đá granit.

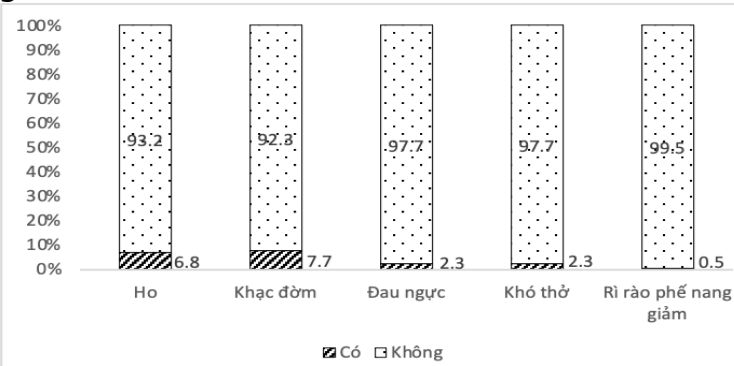

Hình 1: Tỷ lệ người lao động có triệu chứng lâm sàng

Đa số NLĐ tham gia nghiên cứu đều không có các triệu chứng cơ năng, thực thể.
Tỷ lệ NLĐ có các triệu chứng ho, khạc đờm, đau ngực, khó thở, rì rào phế nang giảm lần lượt là $6,8 \%, 7,7 \%, 2,3 \%, 2,3 \%, 0,5 \%$.

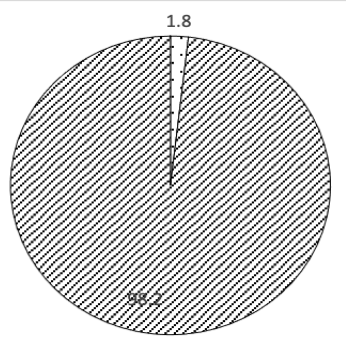

『Có

『Không

Hình 2. Kêt quả phim X-quang theo kỹ thuật ILO của người lao động

Đa số NLĐ tham gia nghiên cứu không có tổn thương đam mờ nhỏ trên phim X-quang theo kỹ thuật ILO. Tỷ lệ NLĐ có tổn thương đám mờ nhỏ trên phim X-quang chỉ chiếm 1,8\%.

Bảng 2. Phân loại kích thước và mật độ tổn thương đám mờ nhỏ trên phim $X-$ quang ở người lao động $(n=4)$

\begin{tabular}{|c|c|c|c|}
\hline \multicolumn{2}{|c|}{$\begin{array}{c}\text { Đặc điểm tổn thướng } \\
\text { đám mờ nhỏ }\end{array}$} & SL & $\%$ \\
\hline \multirow{2}{*}{ Mật độ } & $1 / 1$ & 3 & 75,0 \\
\cline { 2 - 4 } & $1 / 2$ & 1 & 25,0 \\
\hline Kích thước & $\mathrm{p} / \mathrm{p}$ & 4 & 100 \\
\hline \multicolumn{2}{|c|}{ Tống } & 4 & 100 \\
\hline
\end{tabular}

Các tổn thương đám mờ nhỏ trên phim Xquang theo tiêu chuẩn ILO của NLĐ đều thuộc 
phân nhóm chính nhóm 1. Trong đó, tổn thương đám mờ nhỏ có mật đô $1 / 1$ chiếm đa số với 75,0\%. Các tổn thương đám mờ nhỏ có mật độ
$1 / 2$ chỉ chiếm $25,0 \% .100 \%$ các đám mờ nhỏ trên phim X-quang đều có kích thước loại p/p.

Bảng 3. Tỷ lệ người lao động có suy giảm chức năng hô hấp $(n=220)$

\begin{tabular}{|c|c|c|c|c|c|c|}
\hline \multirow{2}{*}{ Các loại rối loạn thông khí } & \multicolumn{6}{|c|}{ Rối loạn thông khí } \\
\cline { 2 - 7 } & \multicolumn{2}{|c|}{ Có } & $\mathbf{3}$ Không & \multicolumn{2}{c|}{ Chung } \\
\cline { 2 - 7 } & SL & $\mathbf{\%}$ & $\mathbf{S L}$ & $\mathbf{\%}$ & $\mathbf{S L}$ & $\mathbf{\%}$ \\
\hline Rối loạn thông khí hạn chế & 24 & 10,9 & 196 & 88,1 & 220 & 100,0 \\
\hline Rối loạn thông khí tắc nghẽn & 14 & 6,4 & 206 & 93,6 & 220 & 100,0 \\
\hline
\end{tabular}

Đa số NLĐ không có rối loạn thông khí. Tỷ lệ NLĐ có rối loạn thông khí hạn chế là $10,9 \%$. Tỷ lệ NLĐ có rối loạn thông khí tắc nghẽn là $6,4 \%$.

\section{BÀN LUÂ̂N}

Nghiên cứu chỉ ra rằng đa số NLĐ tại Phú Yên tham gia nghiên cứu không mắc bệnh bụi phổi silic. Tỷ lệ NLĐ mắc bệnh bụi phổi silic ở các nhà máy là $1,8 \%$. Kết quả này thấp hơn tỷ lệ mắc bệnh bụi phổi silic của NLĐ ở các cơ sở sản xuất vật liệu xây dựng $(7,8 \%)$ trong nghiên cứu của tác giả Lê Thị Hằng [3], và trong nghiên cứu của Gumersindo Rego trên những NLĐ chế tác đá Granite (17,5\%) [4]. Tỷ lệ NLĐ được chẩn đoán mắc bệnh bụi phổi silic tâp trung ở loại hình sản xuất đá granit, chưa phát hiện trường hợp nào của các loại hình sản xuất vật liệu xây dựng khác mắc bênh bụi phổi silic. Có sự khác biệt về tỷ lê mắc bệnh giữa các loại hình sản xuất này có thể do một số lý do sau: thứ nhất do nồng độ bụi silic phát sinh trong các ngành khai thác chế tác đá, đặc biệt là đá Granite cao hơn trong những ngành sản xuất vật liệu xây dựng khác, thứ hai do NLĐ trong nghiên cứu này lao động nặng nhọc, thêm vào đó là không có biện pháp chống bụi hiệu quả nên làm tăng thông khí phổi, dẫn đến tăng hàm lượng bụi silic hít phải vào phổi. Chính vì vậy nên tỷ lệ hiện mắc bệnh bụi phổi silic ở những NLĐ sản xuất đá granit trong nghiên cứu của chúng tôi cao hơn so với những NLĐ ở các loại hình sản xuất vật liệu xây dựng khác. Tuy nhiển kết quả này lại thấp hơn kết quả hiện tại Bình Định năm 2016 khi tỷ lệ hiện mắc chung đối với các ngành khai thác, chế tác đá, sản xuất vật liệu xây dựng là 44,5\% [5]. Sự khác biệt này theo chúng tôi có thể do khác biệt về quần thể nghiên cứu, và ở Bình Định có một số nhà máy khai thác đá nhỏ lẻ, khai thác thủ công là chính, vì vây nguy cơ mắc bênh bui phổi silic ở các ngành khai thác, chế tác đá, sản xuất vật liệu xây dựng ở Bình Định cao hơn. Một lý do khác nữa theo chúng tôi có thể là do những người lao động được phát hiện bệnh bụi phổi silic đã chuyển vị trí việc làm, và có thể các cơ sở sản xuất cũng chú trọng hơn tới việc dự phòng bệnh bụi phổi silic như khám sức khoẻ định kỳ, truyền thông giáo dục sức khoẻ...

Tỷ lệ hiện mắc bệnh bụi phổi silic tập trung chủ yếu ở nhóm lao động nam (2,0\%). Chưa có lao động nữ nào mắc bệnh bụi phổi silic. Có sự khác nhau này là do các vị trí lao động nặng nhọc ở các nhà máy khai thác đá, sản xuất vật liệu xây dựng đều do nam giới đảm nhận nên số người mắc bệnh ở nữ thấp hơn chứ không phải là bệnh hay mắc ở nam giới.

Tỷ lệ hiện mắc bệnh bụi phổi silic của nhóm lao động từ 50 tuổi trở lên là 8,7\%, cao hơn tỷ lệ hiên mắc bênh bụi phổi silic của nhóm lao động dưới 50 tuổi $(1,0 \%)$. Kết quả này cũng phù hợp với đặc điểm sinh lý của con người là khi càng nhiều tuổi, các cơ quan bị quá trình già hoá và có nguy cơ mắc nhiều bệnh tật hơn các lứa tuổi khác. NLĐ khai thác, chế tác đá granit có tỷ lệ mắc bênh bụi phổi silic cao hơn với 2,6\%. Điều này có thể được lý giải do hàm lượng silic trong các loại đá xây dựng nói chung, cũng như đá Granite nói riêng cao hơn so với những nguyên liêu sản xuất vật liệu xây dựng khác. Chính vì vậy, tỷ lệ mắc bệnh bụi phổi silic ở nhóm ngành khai thác, chế tác đá granit cao hơn so với ngành sản xuất vật liệu xây dựng khác.

Kết quả nghiên cứu chỉ ra rằng NLĐ tham gia nghiên cứu các triệu chứng cơ năng, thực thể chỉ chiếm tỷ lệ nhỏ. Tỷ lệ NLĐ có các triệu chứng ho, khạc đờm, đau ngực, khó thở, rì rào phế nang giảm lần lượt là $6,8 \%, 7,7 \%, 2,3 \%, 2,3 \%$, $0,5 \%$. Không có trường hợp NLĐ nào có ran phổi. Đây là các triệu chứng thường gặp phải ở những NLE làm việc trong MTLĐ có phát sinh nhiều bụi. Trong bệnh hô hấp do bụi silic gây ra, ho, khạc đờm thường là triệu chứng xuất hiện sớm nhất. Kết quả của nghiền cứu thấp hơn kết quả nghiên cứu của các tác giả Masoud Zare Naghadehi (năm 2014) khi nghiên cứu về đặc điểm mắc bệnh của những NLĐ tiếp xúc trực tiếp với bụi phổi silic [7].

Có $1,8 \%$ số đối tượng tham gia nghiên cứu có 
tổn thương đám mờ nhỏ trên phim X-quang theo tiêu chuẩn của ILO hướng tới chẩn đoán mắc bệnh bụi phổi silic. Tất cả các đám mờ nhỏ phát hiện trền phim $X$ - quang đều có kích thước loại $\mathrm{p} / \mathrm{p}$ và có mât độ nằm ở phân nhóm chính nhóm 1 , trong đó, đám mờ có mật độ thuộc phân nhóm phụ $1 / 1$ chiếm tỷ lệ cao nhất với $75 \%$, đám mờ có mật độ thuộc phẩn nhóm phụ $1 / 2$ chiếm tỷ lệ $25,0 \%$. Kết quả nghiên cứu tương đồng với kết quả nghiên cứu của nhiều tác giả [6].

Đa số NLĐ không có rối loạn chức năng thông khí phổi, NLĐ có hội chứng hạn chế chiếm tỷ lệ cao nhất 10,9\%; tỷ lệ NLĐ có hôi chứng tắc nghẽn chiếm $6,4 \%$. Kết quả này phù hợp với đặc điểm bệnh lý của bệnh bụi phổi silic là bệnh là xơ hóa phổi dẩn đến giảm dung tích sống gây ra hội chứng hạn chế.

\section{KẾT LUÂNN}

Tỷ lệ hiện mắc bệnh bụi phổi của NLĐ tiếp xúc trực tiếp với bụi silic trong một số ngành nghề tại Phú Yên nằm 2020 là 1,8\%. NLĐ mắc bệnh bụi phổi silic tập trung ở loại hình sản xuất đá granit (100\%). Tỷ lệ NLĐ có các triệu chứng ho, khạc đờm, đau ngực, khó thở, rì rào phế nang giảm lần lượt là $6,8 \%, 7,7 \%, 2,3 \%, 2,3 \%$, $0,5 \%$. Các rối loạn thông khí và tổn thương nhu mô phổi trên phim X - quang mà NLĐ gặp phải đa số là thể nhẹ.

\section{TÀI LIÊU THAM KHẢO}

1. ILO in Vietnam (2013). ILO calls for urgent global action to fight occupational diseases,

<http://www.ilo.org/hanoi/Informationresources/Publi cinformation/Pressreleases/WCMS_211709/lang-vi/index.htm>, xem ngày 10/05/2018.

2. Nguyễn Quảng Thức (2013). Thực trang bệnh nghề nghiêp trên thế giới và ở Việt Nam, $<$ http://moh.gov.vn/pcbenhnghenghiep/pages/tint uc.aspx? CateID $=9 \&$ ItemID $=720>$, xem ngày $10 / 05 / 2018$

3. Lê Thi Hằng, Đào Xuân Vinh, Đoàn Huy Hâu, và cs (2002). Một số đặc điểm dịch tế học bệnh bụi phổi silic ở công nhân sản xuất vật liệu ngành xây dựng. Tạp chí $Y$ học thực hành, 408(2), 73 - 75.

4. Arturo Pichel, Gumersindo Rego, Aida Quero, Alejandro Dubois, Cristina Martínez, (2008). High Prevalence and Advanced Silicosis in Active Granite Workers: A Dose-Response Analysis Including FEV1. Journal of Occupational and Environmental Medicine, 50(7), $827-833$.

5. Trình Công Tuấn (2016). Tình hình bênh Bui phổi Silic tại một số cơ sở khai thác, chế biển đá và sản xuất vật liêu xây dựng tỉnh Bình Định năm 2016, Viện nghiển cứu sức khỏe cộng đồng.

6. Huỳnh Thanh Hà và Trịnh Hồng Lân (2008). Khảo sát tình hình bênh nhiểm bui phổi silic nghề nghiệp tại một số cơ sở sản xuất vật liệu xây dựng thuộc cống ty xây dựng Dĩ An - Bình Dương Tạp chí Y học TP. Hồ Chí Minh, 4(12), 240 - 246.

7. Masoud Zare Naghadehi, Farhang Sereshki, Mohammadi F., (2014). Pathological study of the prevalence of silicosis among coal miners in Iran: A case history. Atmospheric Environment, 83, 1 - 5 .

\section{PHÂN TÍCH DI TRUYỀN TRƯỚC LÀM TỔ $\beta$-THALASSEMIA: MẤT ALEN ĐƯợC KIỂM SOÁT BẰNG PHÂN TÍCH DI TRUYỀN LIÊN KẾT GEN}

Lê Hoàng ${ }^{1}$, Nguyễn Thị Hoa ${ }^{1}$, Nguyễn Liên Hương ${ }^{2}$, Ngô Văn Nhật Minh ${ }^{3}$, Đặng Tiến Trường ${ }^{3}$

\section{TÓM TẮT}

Mục tiêu: Báo cáo một trường hợp gia đình thực hiện PGT-M bênh $\beta$-Thalassemia có xảy ra hiện tượng $A D O$ được phát hiện bằng phương pháp di truyền liên kết gen. Đối tượng và phương pháp: Gia đình nguy cơ gồm người vợ mang dị hợp tữ đột biến Cd17, người chồng mang di hợp tử đột biến $\mathrm{Cd} 26$ và con gái mang hai đột biến dị hợp tử Cd17 và $\mathrm{Cd} 26$. Phương pháp phân tích di truyền trước làm tổ bệnh đơn gen trước làm tổ thông qua xác định haplotype bị bệnh và không

${ }^{1}$ Bênh viên đa khoa Tâm Anh

2Bềnh viện Phụ sản Trung Ương

${ }^{3}$ Hoc viên quân $Y$

Chịu trách nhiệm chính: Đặng Tiến Trường

Email: truongdtvmmu@gmail.com

Ngày nhận bài: 27.10.2020

Ngày phản biên khoa hoc: 26.11 .2020

Ngày duyệt bài: 9.12.2020 bị bệnh, kĩ thuật giải trình tự Sanger để xác định đột biến. Kết quả: Thiết lập được sơ đồ liên kết gen và các đột biến của gia đỉnh nghiên cứu. Kỹ thuật giải trình tự Sanger không đồng nhất với kết quả phẩn tích di truyền liên kết tại một phôi do nguyên nhân ADO. Kết luận: Hiện tượng ADO gây chẩn đoán sai trong PGT. Do đó, viêc áp dụng đồng thời phương pháp trực tiếp và gián tiếp trong PGT-M bệnh $\beta$-thalassemia là rất cấp thiết để khắc phục $A D O$ và cải thiện độ chính xác của PGT.

Tư khóa: $\beta$-Thalassemia, STR, PGT.

\section{SUMMARY}

PREIMPLANTATION GENETIC TESTING ON

B-THALASSEMIA: CASE REPORT ON ALELLE DROP OUT PHENOMENON OBSERVED BY STR-BASED LINKAGE ANALYSIS

Objective: To report one case performing PGT-M on $\beta$-Thalassemia with ADO phenomenon detected by 